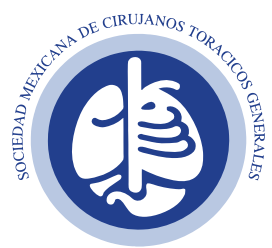

Vol. 1, Núm. 1

Enero-Abril 2020

p 3

\author{
Editorial
}

\title{
Y todo comenzó
}

\author{
And it all began \\ Carlos A Olivares-Torres*
}

Bienvenidos a la revista de la Sociedad Mexicana de Cirujanos Torácicos Generales, en la cual encontrarán diversidad de publicaciones, desde artículos originales y de revisión, hasta casos clínicos y temas de interés para el cirujano torácico general. Ha sido un trabajo iniciado desde antes de la conformación de esta Sociedad Mexicana de Cirujanos Torácicos Generales (SMCTG), con la inquietud de dar a conocer lo que se realiza en nuestro país dentro de la cirugía de tórax, el camino no ha sido fácil, pero con la conformación de nuestra sociedad, hace casi 10 años, esto debe ser parte de una sociedad seria que quiere avanzar y dejar el legado a futuras generaciones de cirujanos torácicos.

La única manera de perdurar es escribir, para eso se llevó a cabo la creación de nuestra revista, desde el diseño de la portada y la selección de los primeros trabajos que encontrarán en nuestro primer número. La mesa directiva junto con los editores que son de lo más destacado de nuestra sociedad, tanto nacionales como extranjeros, trabajaremos para que esto sea un éxito.

Esto nos dará una identidad propia y voz en el desarrollo de nuestra especialidad para fomentar los programas de cirugía torácica general y divulgar lo que se realiza en las diferentes sedes, para hacer crecer la misma dentro y fuera del país.

Esta labor es de todos los cirujanos torácicos generales de México, con esto comenzamos, y en los próximos números y años se alimentará con la participación de todos para que crezca el aporte científico de la misma.

Quiero agradecer a la mesa directiva el nombramiento, el cual lleva mucho peso y trabajo; también a Graphimedic, nuestra casa editorial, en especial a la Dra. María Rosales y su staff, y a Graciela González por toda su ayuda, experiencia y paciencia, es una unión que se dio natural y la colaboración será de beneficio mutuo.

Y pensar que todo esto comenzó hace casi 20 años escribiendo unos nombres en una servilleta.

\footnotetext{
* Editor en jefe. Revista Mexicana de Cirujanos Torácicos Generales.

Correspondencia:

Carlos A Olivares-Torres

E-mail:

editor.revista@smctg.org
}

Citar como: Olivares-Torres CA. Y todo comenzó. Rev Mex Cir Torac Gen. 2020; 1(1):3 